\title{
Os primórdios do ensino de História da Ciência na Faculdade de Ciências da Universidade de Coimbra
}

\author{
Gilberto Pereira \\ Décio Martins \\ Carlos Fiolhais
}

\section{Resumo}

A criação, em 1961, de um Centro de Estudos de Cartografia Antiga, anexo à Faculdade de Ciências e à Faculdade de Letras da Universidade de Coimbra, foi um importante factor que conduziu à introdução na Universidade de Coimbra do ensino da História da Ciência, em particular da História da Ciência Portuguesa. Armando Cortesão, que liderava esse grupo de investigação, ministrou, desde o ano lectivo de 1961/62 até pelo menos 1975, um curso livre sobre história da cartografia. Foi a convite de Armando Cortesão que, em 1962, Reyer Hooykaas, professor de História da Ciência da Universidade Livre de Amesterdão, chegou a Coimbra para proferir duas palestras que, nas palavras de Luís de Albuquerque, 0 professor de Matemática de Coimbra que se notabilizou na História dos Descobrimentos, foram "memoráveis". Hooykaas considerava que todo o cientista, pelo menos de um modo geral, deveria conhecer a história do desenvolvimento da sua própria ciência, "os seus avanços, conquistas e recuos". Em 1963 e 1964 Hooykaas leccionou um curso livre intitulado "Introdução à História da Ciência", que descreveu os feitos científico-técnicos alcançados pelos portugueses ao longo da expansão marítima iniciada no século XV. A reforma do ensino de 1964-65 introduziu oficialmente o ensino da História da Ciência na Faculdade de Ciências da Universidade de Coimbra. Tornava-se nessa altura evidente a necessidade desta disciplina para formar cientistas e professores.

Palavras-chave: Universidade de Coimbra; Reyer Hooykaas; Armando Cortesão; Luís Albuquerque.

\begin{abstract}
The creation in 1960 of a Center for Ancient Cartography Studies associated with the Faculty of Sciences and the Faculty of Arts and Humanities, was a key factor which led to the modern introduction of the teaching of History of Sciences at the University of Coimbra, in particular History of Science in Portugal. Armando Cortesão, who was the head of this research group, was responsible for teaching a free course on ancient cartography every year (a course he taught since the school year of 1961/62 at least until 1975). Reyer Hooykaas, professor of History of Science at the Free University of Amsterdam, arrived in Coimbra in 1962 at the invitation of Armando Cortesão, to deliver two lectures that, in the words of Luís de Albuquerque, professor of Mathematics in Coimbra who became famous in the History of Portuguese Discoveries, were "memorable". Hooykaas considered that every scientist, at least in general, should know the history of the development of his own science, "its hopes, conquests and recoils". In 1963, 1964 and 1967, Hooykaas started teaching a free course entitled "Introduction to the History of Science", where he described the scientific and technical achievements of the Portuguese during the maritime expansion which started in the 15th century. The teaching reform of 1964-65 introduced officially the teaching of the History of Science in the Faculty of Sciences of the University of Coimbra. By then it was clear the need for this new discipline to form scientists and teachers.
\end{abstract}

Keywords: University of Coimbra; Reyer Hooykaas, Armando Cortesão; Luís Albuquerque.

\section{INTRODUÇÃO}


A reforma do ensino de 1964-1965 introduziu o ensino da História da Ciência na Faculdade de Ciências da Universidade de Coimbra (UC). Esta inovação no programa curricular foi consequência de alguns factos que tornaram clara a necessidade desta nova disciplina na formação de cientistas e professores.

Um desses primeiros factos foi a realização em 1936 do $3{ }^{\circ}$ Encontro Internacional de História da Ciência em Portugal, que trouxe ao Porto, Coimbra e Lisboa nomes relevantes da História da Ciência, como o belga George Sarton ou a francesa Hélène Metzger. Em Coimbra realizaram-se secções plenárias, onde se nota, no quadro de oradores, a ausência de professores da Faculdade de Ciências de Coimbra. Com a morte de Luciano Pereira da Silva (1864-1926) ${ }^{1}$ tinha-se perdido a grande referência da investigação histórica naquela Faculdade. Este encontro internacional teve como consequência, embora indirecta, a reorganização do Gabinete Pombalino de Física, encetada por Mário Augusto da Silva, em 19372 .

Os congressos bianuais das Associações Espanhola e Portuguesa para o Progresso das Ciências (que se realizavam desde 1921, e que passaram por Coimbra em 1925 e em 1956), foram encontros muito úteis para a divulgação das investigações científicas realizadas na Península lbérica, mas também para relevar o papel da História da Ciência. O Professor de Física da Faculdade de Ciências da Universidade do Porto Carlos de Azevedo Coutinho Braga (1899-1982), no discurso inaugural da secção de Física e Química do Congresso de 1956, discorreu sobre os "50 anos de Progresso em Física (19051955)"3. Para além de enumerar os avanços na Física na primeira metade do século XX, salientou a relação entre o progresso da ciência e o progresso da humanidade. E o primeiro progresso só é possível conhecendo a história da ciência, como defendeu no mesmo encontro Arnaldo de Miranda e Barbosa (1916-1973), Professor de Filosofia da Faculdade de Letras da Universidade de Coimbra:

O cientista, em determinada época, não tem de reedificar a ciência desde os fundamentos. Para avançar na aventura da descoberta, parte de trilhos condutores já desbravados. Pode criticar métodos, enjeitar resultados, substituir hipóteses, desmentir

\footnotetext{
${ }^{1}$ Professor de Matemática, especialista em História dos Descobrimentos e da Náutica. Ver: "Luciano P. de Silva (1864-1926)", Ciência em Portugal, Instituto Camões, http://cvc.institutocamoes.pt/ciencia/p33.html (acedido em 19 de Fevereiro de 2019).

${ }^{2}$ Não sabemos se Mário Silva assistiu às palestras, mas sabemos que algumas das comunicações foram realizadas no anfiteatro do Laboratório de Física. Para saber mais sobre o trabalho encetado por Mário Silva ver: Gilberto Pereira, "A reorganização do Museu Pombalino de Física da Universidade de Coimbra por Mário Augusto da Silva," Conservar Património 26 (2017): 23-36.

3 XXIII Congresso Luso-Espanhol para o Progresso das Ciências, Tomo I (Coimbra: Coimbra Editora Lda., 1956), 81-107.
} 
experiências, inverter teorias. Mas o seu trabalho não é criação ex-nihilo: é momento integrado em processo evolutivo. ${ }^{4}$

É esta premissa que torna o ensino da História da Ciência uma necessidade para os programas dos cursos universitários de ciências exactas e naturais. Muito provavelmente o ponto de inflexão para que esta alteração ocorresse foi a contratação de Armando de Freitas Zuzarte Cortesão (1891-1977) como docente convidado da Faculdade de Ciências.

\section{O CuRso de História da CARtografia Portuguesa, por ARMANdo Cortesão}

Na reunião da Congregação dos professores catedráticos da Faculdade de Ciências de 13 de Outubro de 1960, o director da Faculdade, António Jorge de Andrade de Gouveia (1905-2002), professor de Química que mais tarde haveria de ser reitor, deu a conhecer um projecto de criação de um Centro de Estudos de Cartografia, que ficaria associado às Faculdades de Letras e de Ciências. Sugeriu também a contratação do "Eng. Armando Cortesão para reger um curso sobre o assunto"5. Este Centro ficaria provisoriamente instalado na Faculdade de Letras (que possuía um novo e amplo edifício), devendo depois ser transferido para o novo edifício que estava projectado para a Secção de Matemática da Faculdade de Ciências, e que haveria de ser inaugurado em 1969. Nesta reunião foi aventada a possibilidade de abordar a Junta das Missões Geográficas e de Investigações do Ultramar pedindo apoio para este projecto, visto ser esta uma instituição vocacionada para o estudo da cartografia das colónias (a proposta seria apresentada em 27 de Dezembro de 1960)6 ${ }^{6}$.

Em 1960 Armando Cortesão, engenheiro agrónomo reformado, tinha já uma grande reputação na história da cartografia antiga ${ }^{7}$. Nesse ano começou a publicar, juntamente com o comandante Avelino Teixeira da Mota (1920-1982), a Portugaliae Monumenta Cartographica, uma grandiosa obra em seis volumes, com numerosos mapas históricos e respectivas descrições. A relação de Armando Cortesão com a Faculdade de Ciências já existia, pois ele frequentava a Biblioteca Matemática, onde se encontrava o legado deixado por Luciano Pereira da Silva e pelo discípulo deste, o historiador António Barbosa (1892-

\footnotetext{
${ }^{4}$ Ibid., 166.

5 Actas da Faculdade de Ciências (1960-1972), 17v. Cota no Arquivo da Universidade de Coimbra (AUC): IV-1aD-3-1-53-C.

6 António A. de Gouveia, "Vida da Faculdade: 1960-1961 - Relatório," Revista da Faculdade de Ciências 30 (1961): XVII.

7, "Armando de F. Zuzarte, Coimbra, 1891 - Lisboa, 1977," Dicionário de Historiadores Portugueses, http://dichp.bnportugal.pt/historiadores/historiadores cortesao armando.htm (acedido em 19 de Fevereiro de 2019).
} 
1946) $)^{8}$. Sabemos também que Cortesão cultivou uma forte amizade com o anterior director da Faculdade, João Pereira da Silva Dias (1894-1960), professor de Matemática então recentemente falecido (a 13 de Setembro).

O Conselho Escolar da Faculdade de Ciências, reunido em 23 de Janeiro de 1961, reconheceu a falta de um curso de História da Cartografia Portuguesa na formação dos escolares portugueses, assim como "a influência que o tratamento destes assuntos, em alto nível, poderá ter na investigação de tão aliciante e patriótica matéria" 9 . Nessa reunião, Andrade Gouveia informou os seus colegas de que 0 Ministro do Ultramar "homologou a nomeação do Eng. ${ }^{\circ}$ Armando Cortesão como dirigente do Agrupamento de Estudos de Cartografia Antiga, anexo à Universidade de Coimbra e concedeu ao referido agrupamento a dotação de $200.000 \$ 00 " 10$.

O Agrupamento de Estudos de Cartografia Antiga da Universidade de Coimbra, tal como proposto pelo Conselho Escolar da Faculdade de Ciências da Universidade de Coimbra, foi criado em 1961, sob a tutela da Junta das Missões Geográficas e de Investigações do Ultramar ${ }^{11}$. A relação entre a Faculdade de Ciências e a Junta das Missões já existia através de um outro Centro de Estudos, sediado em Coimbra desde 1956: o Agrupamento Científico de Estudos Ultramarinos ${ }^{12}$, com secções de Física, Química, Geologia, Botânica, Zoologia, Antropologia e Etnografia. Este facto terá certamente facilitado 0 apadrinhamento deste novo grupo dirigido por Armando Cortesão, com a colaboração do professor de Matemática, Luís Guilherme Mendonça de Albuquerque (1917-1992). Luís de Albuquerque, matemático e engenheiro geográfico de formação, era o professor da cadeira de Álgebra e iria tornar-se, na esteira do trabalho de Luciano Pereira da Silva, uma figura eminente na História da Ciência e da Educação em Portugal, autor de uma extensa biografia dedicada ao assunto ${ }^{13}$.

Tal como previsto, este centro de estudos foi rapidamente instalado na Faculdade de Letras onde já se encontrava em actividade em 28 de Fevereiro de 1961 - já com o plano de vir a ter instalações

\footnotetext{
8 Carlos Tenreiro, A Biblioteca Matemática da Universidade de Coimbra (Coimbra: Imprensa da Universidade de Coimbra, 2014).

${ }^{9}$ Processo dos professores. Cota no AUC: IV-1aD - caixa 44.

${ }^{10}$ Actas da Faculdade de Ciências (1960-1972), 24v. Cota no AUC: IV-19D-3-1-53-C.

${ }^{11}$ Instituição onde já existia um agrupamento similar, o Centro de Estudos de Cartografia e Geografia Colonial, criado em 1946 em Lisboa.

12 Este Centro tinha por função orientar os assistentes, técnicos e estudantes adiantados para o estudo do património do ultramar. O grande número de artigos publicados na Faculdade de Ciências da UC sob o seu patrocínio evidencia uma grande actividade (principalmente estudos de química, mineralogia, petrologia, geologia, botânica, paleontologia e etnografia). Através deste centro a Faculdade de Ciências estabeleceu relações de cooperação com outros centros congéneres da Junta das Missões. Ver: João P. Dias, "Vida da Faculdade: 1956-1957 - Relatório do Director," Revista da Faculdade de Ciências 26 (1957): IX.

${ }^{13}$ Fernando Duval Chaves Ferreira, org., Luís de Albuquerque: Historiador e Matemático. Homenagem de Amizade a um Homem de Ciência (Chaves Ferreira - Publicações, S.A., 1998).
} 
definitivas no edifício do actual Departamento de Matemática ${ }^{14}$. Entretanto, devido às condições precárias das instalações na Faculdade de Letras, no início de 1964 o Agrupamento de Estudos de Cartografia Antiga foi transladado para novas acomodações no Instituto de Antropologia situado no Colégio de São Bento (instalações recentemente renovadas pelas obras da Cidade Universitária), sendo reinstalado definitivamente no edifício da Matemática apenas em 197015. Dentro dos seus objectos, o Agrupamento de Estudos de Cartografia Antiga:

(...) procura desenvolver-se num instrumento de trabalho que possa não só ser utilizado por estudiosos dos problemas da história da cartografia e da ciência náutica, mas também publicar trabalhos próprios. Para isso dispõe do rico conjunto de obras de cartografia náutica e descobrimentos pertencente à Biblioteca de Matemática, a que se juntaram agora os livros do mesmo género, fotografias de cartas antigas e alguns instrumentos, doados pelo Doutor Armando Cortesão à nossa Biblioteca; é já a melhor biblioteca desta especialidade em Portugal e espera-se que venha a ser uma das melhores do mundo. A secção conta, no próximo ano, com a colaboração dos professores Doutores Fernandes Martins, Salvador Arnaud e Luís Ferrand de Almeida, devendo assim intensificar-se a publicação de trabalhos originais e reedições anotadas e com estudos críticos, já este ano iniciadas. ${ }^{16}$

A unanimidade sobre o brilho do trabalho de Armando Cortesão comprova-se pela atribuição pela Universidade de Coimbra, em 23 de Abril de 1961, do grau de Doutor Honoris Causa em Ciências Matemáticas. Na cerimónia esteve presente o Ministro do Ultramar, Adriano Moreira17, sendo Armando Cortesão apresentado por João Carrington Simões da Costa, Presidente da Comissão Executiva da Junta de Investigações do Ultramar, e sendo oradores os professores da casa Manuel dos Reis ${ }^{18}$ (1900-1992) e Luís de Albuquerque.

\footnotetext{
${ }^{14}$ Sobre este assunto ver: Actas da Faculdade de Ciências (1960-1972), 27, 105, 111v e 224V. Cota no AUC: IV-1aD-3-1-53-C.

15 No actual Departamento de Matemática da UC, as três salas originais que ocupava o Agrupamento de Estudos de Cartografia Antiga deram origem ao Instituto de História da Náutica, com apenas uma sala, onde se encontra o seu espólio.

16 António A. de Gouveia, "Vida da Faculdade: 1960-1961 - Relatório," Revista da Faculdade de Ciências 30 (1961): XVII.

17 António A. de Gouveia, "Vida da Faculdade: 1960-1961 Relatório," Revista da Faculdade de Ciências 30 (1961): XI.

18 Segundo o relatório do director da Faculdade de Ciências, para o ano de 1960-1961, Manuel dos Reis foi nomeado vogal da Comissão Nacional da «Union Internationale d'Histoire des Sciences», sob proposta da direcção do Instituto de Alta Cultura. Ibid.
} 
Apesar desta distinção, a contratação de Armando Cortesão sofreu alguns percalços. A intenção da Faculdade de Ciências era contratar este estudioso como "professor catedrático com a última diuturnidade", ao abrigo do decreto-lei n. ${ }^{\circ} 31728$, que permitia a realização de contratos com pessoas notáveis, o que foi aprovado por despacho da Direcção Geral do Ensino Superior e das Belas Artes (em 26 de Maio de 1961) $)^{19}$, ficando Armando Cortesão encarregue de ministrar lições sobre História da Cartografia Portuguesa. Porém, a sua situação de aposentado não permitia a sua contratação sem a prévia autorização do Conselho de Ministros. O Director da Faculdade apelou então ao reitor da UC para interceder sobre este assunto (em 21 de Julho de 1961) e, finalmente, um ofício assinado por António de Oliveira Salazar (em 15 de Novembro de 1961), aprovou a realização de contrato em prestação de serviços. A ligação de Armando Cortesão à UC perduraria para além da Revolução de 25 de Abril de $1974^{20}$.

Uma das principais actividades do novo Agrupamento foi o curso de História da Cartografia Portuguesa ministrado por Armando Cortesão, o qual era constituído por uma série de lições, com o seguinte programa:

Definição. Interesse e importância da história da cartografia.

Historiadores da cartografia, portugueses e estrangeiros. Portugaliae Monumenta Cartographica.

Cartografia clássica.

Marino de Tiro e Ptolomeu - Escola de Alexandria.

Romanos e Baixa Idade Média.

Século XIII, génese do espírito científico do Renascimento, «carta portulano».

Século XIV - Primórdios das navegações e cartografia portuguesas.

Cartografia do Infante.

Projecção, construção e uso da carta, e problema da longitude.

Duarte Pacheco, Pedro Nunes, D. João de Castro e outros.

\footnotetext{
19 Processo dos professores. Cota no AUC: IV-1 $1^{\mathrm{a} D}$ - caixa 44.

20 No Arquivo da Universidade de Coimbra encontramos as notas de pagamento a Armando Cortesão desde Janeiro de 1962 (8100\$00) (cota no AUC: II-1a D-4-4-18) até Dezembro de 1967 (cota no AUC: II-1a D-4-4-23). Todavia em 1970 Armando Cortesão solicita ao Ministério da Educação Nacional o reforço da verba inscrita no orçamento do Ministério por onde são pagos os seus vencimentos (cota no AUC: IV-1 aD - caixa 44). E em 1975-01-17 um ofício da Faculdade informar o reitor sobre o pagamento ( $200400 \$ 00$ anuais) e pelos serviços auxiliares que seriam prestados por ele: Regência de um Curso Livre de Cartografia Antiga com duração de um semestre. Trabalho de investigação e preparação para publicação das seguintes obras: História da Cartografia Antiga (com dois volumes já publicados e o terceiro volume em preparação); Cartas de Londres; Esparsos (primeiro volume já publicado e dois volumes em provas); Obras completas de D. João de Castro - de colaboração com o Prof. Doutor Luís Guilherme Mendonça de Albuquerque, em curso de publicação (Ibid.).
} 
Cartografia do século XVI.

Influência da cartografia portuguesa na cartografia estrangeira.

Do século XVII ao século XX. ${ }^{21}$

Sabemos que o primeiro curso foi ministrado no ano lectivo de 1961-1962, e que, pelo menos a partir do ano lectivo de 1963-1964, Armando Cortesão teve a colaboração de Luís de Albuquerque e do comandante Teixeira da Mota na regência deste curso livre, que era ministrado anualmente ${ }^{22}$. As dez lições proferidas (Cortesão responsável por seis, Albuquerque e Teixeira da Mota, por duas respectivamente) foram compiladas numa pequena publicação devido ao "interesse de que se revestiram e pelo que esta matéria representa para a História da Geografia Universal"23. O curso de 1969 foi ministrado unicamente por Armando Cortesão, num conjunto de oito conferências, seguidas de discussão livre, proferidas num anfiteatro do Instituto de Antropologia24. Em 10 de Dezembro de 1970 iniciaram-se as dez lições do curso de 1970-1971, desta vez proferidas no edifício da Matemática e a cargo de Cortesão e Albuquerque ${ }^{25}$.

No trabalho do Agrupamento, para além deste curso, destacamos 0 acolhimento de investigadores estrangeiros que consultavam a sua biblioteca, como foi o caso de Miguel Metzeltin (da Universidade de Basileia) e de Helmut Peter Schwake (da Universidade de Heidelberg) ${ }^{26}$. Também se salienta uma homenagem a Luciano Pereira da Silva, aquando do primeiro centenário do seu nascimento, tendo sido decidido elaborar um número especial da Revista da Faculdade de Ciências em sua honra. Por sugestão de João Rodrigues de Almeida Santos (1906-1975), professor da secção de Física, deveriam convidar-se "entidades brasileiras (e talvez também a inglesas) para colaborarem"27 nesse número, visto que a sua obra tinha alcançado uma grande projecção no Brasil. Embora este projecto fosse de 1964, apenas em 1967 foi publicado um extenso volume com 17 artigos, versando temas da história da astronomia e da náutica portuguesa ${ }^{28}$. Outro grande acontecimento organizado por este Agrupamento foi a I Reunião Internacional de História da Náutica, realizada entre 23 e 26 de Outubro de 1968, na

\footnotetext{
${ }^{21}$ Ibid.

22 João Cotelo Neiva, "Vida da Faculdade (1963-1964): Relatório," Revista da Faculdade de Ciências 34 (1967): V-VI.

23 Armando Cortesão, Luís de Albuquerque e Avelino Teixeira da Mota, "Curso de história da cartografia," Boletim do Centro de Estudos Geográficos 3, no 20 (1963): 139-190.

24 Armando Cortesão, Folheto publicitário do Curso de história da cartografia portuguesa: para estudantes e pós-graduados (Universidade de Coimbra, 1969).

${ }^{25}$ Armando Cortesão e Luís de Albuquerque, Folheto publicitário do Curso de história da cartografia e da náutica: para estudantes e pós-graduados (Universidade de Coimbra, 1970-1971).

26 João Cotelo Neiva, "Relatório referente ao ano lectivo de 1966-1967," Revista da Faculdade de Ciências 40 (1967): XI.

${ }^{27}$ Actas da Faculdade de Ciências (1960-1972), 114. Cota no AUC: IV-19aD-3-1-53-C.

28 Manuel Nunes Dias (Universidade de São Paulo), David W. Waters (National Maritime Museum, Greenwich), foram alguns dos autores presentes. Ver: Revista da Faculdade de Ciências, 39 (1967).
} 
Universidade de Coimbra, com um programa com 25 palestras, das quais mais de metade foram proferidas por estrangeiros $(14)^{29}$.

Para o registo da produção historiográfica do Agrupamento de Estudos de Cartografia Portuguesa foi criada, logo em 1961, a publicação Série Separatas, cujo primeiro número ficou a cargo da secção de Lisboa e o segundo sob responsabilidade da secção de Coimbra (por Luís de Albuquerque) ${ }^{30}$. Para os trabalhos de maior vulto foi criada, em 1963, a Série Memórias. Até 1972 a secção de Coimbra publicou 46 trabalhos: 7 volumes na Série Memórias e 39 volumes da Série Separatas ${ }^{31}$.

Pelo decreto-lei n. ${ }^{\circ} 583$ de 1973, que redefiniu as competências e a orgânica da Junta de Investigações Científicas do Ultramar, o Agrupamento de Estudos de Cartografia Antiga passou a integrar o recém-criado Centro de Estudos de Cartografia Antiga. Em 1982, Luís de Albuquerque assumiu a direcção nacional deste Centro, que passado pouco tempo (decreto-lei n. ${ }^{\circ} 160$ de 1983) foi novamente renomeado para Centro de Estudos de História e Cartografia Antiga, integrado no Instituto de Investigação Científica e Tropical, entidade que substituiu a antiga Junta de Investigações Científicas do Ultramar.

\section{O CURSO dE INTRODUÇÃO À HISTÓRIA DA CIÊNCIA, POR REYER HOOYKAAS}

No âmbito das suas competências no Agrupamento de Estudos de Cartografia Antiga, Armando Cortesão sugeriu ao Reitor da Universidade de Coimbra, com o apoio do Conselho Escolar da Faculdade de Ciências (1961-10-12)32, que se convidasse o historiador holandês Reyer Hooykaas (1906-1994), para proferir duas palestras em Coimbra.

Hooykaas, que tinha sido pioneiro no ensino universitário da História da Ciência na Holanda, era professor dessa disciplina na Universidade Livre de Amesterdão desde o fim da Segunda Guerra Mundial, para além de ser membro desde 1959 da Academia Real das Artes e Ciências da Holanda. Formado em Química, defendeu a sua tese de doutoramento em 1933, onde abordava o conceito de elemento e seu desenvolvimento histórico-filosófico. Era especialista em questões históricas relativas à relação entre ciência e a religião, assim como na história da cristalografia ${ }^{33}$.

\footnotetext{
${ }^{29}$ Discursos e Comunicações. I Reunião Internacional de História da Náutica (Coimbra: Universidade de Coimbra, Estudos de Cartografia Antiga, 1970), 614.

30 O primeiro texto é assinado pelo comandante Teixeira da Mota ("Cinco séculos de cartografia das Ilhas de Cabo Verde") e o segundo por Luís de Albuquerque ("Os Almanaques Portugueses de Madrid").

31 Prospecto da Faculdade: 1973-1974 (Coimbra: Coimbra Editora, Lda., 1973).

${ }^{32}$ Actas da Faculdade de Ciências (1960-1972), 43v. Cota no AUC: IV-1aD-3-1-53-C.

33 H. F. Cohen. "Eloge Reijer Hooykaas, 1 August 1906-4 January 1994," Isis 89, no 1 (1998): 181184.
} 
As suas palestras foram proferidas nos dias 6 e 7 de Novembro de 1962, sob o título L'histoire des sciences, ses problèmes, sa méthode, son but ${ }^{4}$. No texto, publicado em francês na Revista da Faculdade, encontramos várias referências a autores portugueses, na sua língua original, como Garcia de Orta, Almeida Garrett, Oliveira Martins, ou Joaquim de Carvalho, o que demonstra um grande conhecimento da cultura portuguesa. Para Hooykaas:

(...) l'écroulement de la conception antique du monde commença quand les Portugais démontrèrent, non pas par des arguments subtils, mais par des faits solides que le monde est tout autre que les Grecs ne l'avaient supposé; qu'il y a des antipodes et que la zone torride est habitable. ${ }^{35}$

Relativamente à importância do ensino da História da Ciência na educação científica, Hooykaas defendia que:

Naturellement l'histoire des sciences ne joue pas le même rôle dans l'éducation d'un scientiste que remplit l'histoire de la philosophie ou de la théologie dans la formation d'un philosophe ou d'un théologien. Dans les sciences de la nature les théories d'autrefois en général n'ont aucune valeur. Si elles sont restées actuelles, on les retrouve (parfois modifiées profondément) incorporées dans les manuels et on n'a pas besoin de traités d'histoire pour les connaître.

Pourtant l'étude de l'histoire est utile pour l'éducation d'un homme de science, parce qu'elle contribue à le rendre philosophe de la nature au lieu de simple artisan spécialisé. (...) La véritable cultivation d'une science est plus que son application dans le monde extérieur; elle inclut la critique de la connaissance, la méditation sur ses fondaments, la confrontation avec les autres aspects de la réalité. ${ }^{36}$

O impacto das palestras proferidas por Hooykaas foi tão marcante que o director da Faculdade encetou contactos, ainda em 1962, para angariar financiamento de um curso sobre História da Ciência, a ser ministrado pelo professor holandês. Em Janeiro de 1963 já as viagens do professor holandês estavam asseguradas por um financiamento do Instituto da Alta Cultura (IAC) $)^{37}$. A sua estadia foi custeada pela

\footnotetext{
34 Reyer Hooykaas, "L'histoire des sciences, ses problèmes, sa méthode, son but," Revista da Faculdade de Ciências 32 (1963): 5-35.

35 Ibid., 20.

36 Ibid., 8.

37 Actas da Faculdade de Ciências (1960-1972), 72. Cota no AUC: IV-1ad-3-1-53-C.
} 
Fundação Gulbenkian (com 16000\$00), tendo este primeiro curso decorrido entre 22 de Abril e 15 de Maio de 1963 ${ }^{38}$. Composto por um conjunto de 12 lições, o curso foi, segundo o director da Faculdade, seguido "com muito interesse e boa frequência"39. A escolha dos temas tratados, segundo Hooykaas, "foi determinada sobretudo pela necessidade de apresentar a transição da ciência antiga para a ciência moderna, e de mostrar em que medida a tradição antiga continua ainda hoje viva"40. Hooykaas, que se tinha tornado poliglota - dada a necessidade como historiador de ler textos nas línguas maternas - chegou a expressar-se em português durante o curso. Os temas versados foram os seguintes:

1 - A ciência na antiguidade

2 - Aristóteles

3- A Idade Média

4 - A teoria qualitativa em química

5 - O nascimento da ciência moderna

6-O mecanicismo

7 - 0 método da ciência moderna

8 - Newton e a ciência no século XVIII

9 - A revolução química. As leis da conservação

10 - A teoria atómica

11 - A classificação e a teoria biológicas

12 - Ciência e história

Em 1964 Hooykaas ministrou o seu segundo curso, de novo tornado possível com a ajuda financeira do IAC e da Fundação Gulbenkian. Entre quatro propostas apresentadas para tema do curso, a Congregação da Faculdade de Ciências optou pelas duas seguintes: " "História da teoria atómica e molecular» e «Evolução e noção das espécies (em Química, Mineralogia e Biologia)»"41.

A continuação deste curso foi discutida no ano seguinte, dentro da Congregação. O novo director da Faculdade de Ciências, o professor de Geologia João Manuel Cotelo Neiva (1917-2015), concordou com a realização da terceira edição (sugerida em 13 de Maio de 1965 pelo seu antecessor, Andrade Gouveia, que entretanto tinha sido eleito reitor), defendendo que convinha "aproveitá-lo para ir preparando

\footnotetext{
38 Ibid., $73 \mathrm{v}$.

39 Ibid., 77.

40 O curso, publicado na revista da Faculdade, foi traduzido do francês por alguns estudantes e revisto por Luís de Albuquerque. Ver: Reyer Hooykaas, "Introdução à História das Ciências," Revista da Faculdade de Ciências 32 (1963): 203-389.

${ }^{41}$ Actas da Faculdade de Ciências (1960-1972), 108v. Cota no AUC: IV-1aD-3-1-53-C.
} 
quem um dia reja o curso de História da Ciência, da nova Reforma"42. Nessa sessão da Congregação da Faculdade, foi referido que "Hooykaas fora nomeado pela Rainha da Holanda cavaleiro da Ordem do Leão Holandês em virtude dos seus trabalhos realizados na Academia das Ciências, e das relações científicas que estabelecera no estrangeiro, em especial em Portugal"43.

De facto, passado mais de um ano, a Congregação da Faculdade (1966-10-17) mostrou-se preocupada em preparar professores ou assistentes para a regência desta disciplina. Uma das possibilidades seria que se "oficiasse a todo o corpo docente no sentido de nos informarmos de quem poderia estar interessado em dedicar-se a esses temas"44, visto que a contratação permanente de um professor estrangeiro estava posta de lado. Luís de Albuquerque, que entretanto tinha sido nomeado professor catedrático estando presente na reunião nessa condição, "informou que o Dr. Hooykaas estaria disposto a dar-nos ajuda, mas que não Ihe seria possível dá-la por mais de um ano"45. Ficou encarregue de combinar um último curso. A Faculdade decide então "encontrar dois professores ou assistentes que se dispusessem a dedicar-se ao tema, sendo um de formação em Físico-Química e outro de formação em Ciências Naturais"46. Luiz Paulo Manuel de Menezes de Mello Vaz de Sampayo (1920-2006), assistente do grupo de Física, com gosto particular pelos temas da genealogia e da heráldica, aceitou o repto. Faltava encontrar o segundo.

Entretanto as datas para o novo curso com o professor Hooykaas (que tinha já aceite dar um curso de um mês e orientar dois assistentes) demoravam a ser definidas e a Faculdade decidiu indicar (em 13 de Junho de 1967)47 o nome do professor de Matemática Manuel Neto Murta (1919-1992) para a regência da cadeira de História do Pensamento Matemático (depois de Manuel dos Reis, decano do grupo de Matemática, declinar o convite para assegurar essa regência). A situação leva-nos a questionar sobre a razão pela qual Luís de Albuquerque, que estava presente nesta reunião da Congregação, não tenha sido o escolhido, devido ao seu percurso e domínio das matérias a leccionar. Talvez o impedimento tenha sido a sua vontade de ir em comissão de serviço para os Estudos Gerais de Moçambique ${ }^{48}$. Para a cadeira de

\footnotetext{
42 Ibid., $141 \mathrm{v}$.

${ }^{43}$ Ibid., $141 v$.

44 Ibid., $167 v$.

45 Ibid., $167 v$.

${ }^{46}$ Ibid., 169.

47 Ibid., $177 \mathrm{v}$.
}

48 Luís de Albuquerque foi inicialmente nomeado (por portaria de 1966-1-17) para desempenhar em comissão de serviço as funções de professor extraordinário nos Estudos Gerais Universitários de Moçambique e, a seu pedido (portaria de 1966-03-21), foi exonerado do cargo pouco tempo depois, não tendo ido leccionar para África. Posteriormente foi novamente nomeado em comissão de serviço para a mesma Universidade, mas agora como professor catedrático (portaria de 22 de Dezembro de 1967), lugar de que tomou posse em 1968-5-24, e no qual permaneceu até 1970-08-05. Nesse período em que Luís de Albuquerque esteve destacado em Comissão de Serviço fora da UC, proferiu na Universidade de Moçambique, em doze lições, um curso de História da Náutica (1968-1969), tendo repetido esse curso em Setembro de 1969, desta vez no Rio de Janeiro. O conteúdo encontra-se 
História da Ciência, os nomes indicados foram os de Abílio Fernandes (decano das Ciências Naturais) e Luiz Sampayo.

O Reitor propôs (em 26 de Junho de 1968)49 que a Faculdade demonstrasse publicamente a sua gratidão a Hooykaas, conferindo-lhe o grau de Honoris Causa, que este aceitou, declinando porém, com lástima, não lhe ser possível realizar o terceiro curso de História da Ciência. A cerimónia solene aconteceu em 13 de Março de 1969, tendo o professor holandês sido apresentado por Armando Cortesão e os elogios feitos por Luís de Albuquerque e Luiz Sampayo50.

A ligação de Hooykaas com Portugal foi não só intensa como marcante no seu trabalho como historiador da Ciência. Hooykaas, para além de aprender português, como já vimos, dedicou parte da sua investigação a alguns episódios sobre as descobertas marítimas portuguesas e a sua influência na ciência moderna $^{51}$.

\section{A REFORMA dO ENSINO DE 1964-1965 E O ENSINO dA HISTÓRIA DA CIÊNCIA}

Nas Actas da Congregação da Faculdade de Ciências, principalmente as realizadas depois do fim da Segunda Guerra Mundial, é notório um aumento dos pedidos de reforma do ensino universitário, por parte dos professores da UC. A ciência tinha evoluído e especializado a uma ritmo tal que os programas curriculares estavam ultrapassados, tornando premente uma actualização de conteúdos. Em 1954, o Ministro da Educação Nacional previa rever o plano de estudos das Faculdade de Ciências, de forma a incluir "matérias respeitantes à física nuclear, à radioquímica, à electrónica e às suas aplicações" (decreto-lei 39580). Porém, essas reformas só foram concretizadas no ano lectivo de 1964-1965, tendo sido João de Almeida Santos, director do Laboratório de Física da UC, o professor responsável pelas negociações a este respeito com o Mistério da Educação.

A publicação da reforma do Plano de Estudos das Faculdades de Ciências, (decreto n. ${ }^{0} 45840$ de 31 de Julho de 1964), corresponde à maior transformação dos planos curriculares desde 1911. Elevou de 46 a 99 o número de disciplinas professadas na Faculdade de Ciências e as licenciaturas passaram de

publicado em: Luís de Albuquerque, Curso de História da Náutica: Comemorações do Centenário do Almirante Gago Coutinho 1869-1969 (Rio de Janeiro: Serviço de Documentação Geral da Marinha, 1971).

49 Actas da Faculdade de Ciências (1960-1972), 201v. Cota no AUC: IV-1aD-3-1-53-C.

50 Ibid., 205v.

51 A este propósito, ver: Reyer Hooykaas, "The Portuguese Discoveries and the Rise of Modern Science," Boletim da Academia Internacional da Cultura Portuguesa 2 (1966): 88-107; Reyer Hooykaas, "The Impact of the voyages of discovery on Portuguese humanist literature," Separata do Agrupamento de Estudos de Cartografia Antiga 45 (1970): 1-16; Reyer Hooykaas, "The Erasmian influence on D. João de Castro, 1979", Separata do Centro de Estudos de Cartografia Antiga 114 (1979): 1-29. 
quatro para cinco anos. A licenciatura em Ciências Histórico-Naturais deu origem às licenciaturas em Biologia e em Geologia. De igual forma, a licenciatura em Ciências Físico-Químicas dividiu-se em duas. E, na secção das Ciências Matemáticas, surgem as licenciaturas em Matemática Pura e em Matemática Aplicada. O novo plano curricular foi implementado no ano lectivo de 1964-65, para os alunos matriculados pela primeira vez.

No que diz respeito ao ensino da História da Ciência, a nova cadeira anual de História do Pensamento Matemático foi implementada em ambas as licenciaturas em Matemática, sendo ministrada no $4 .^{\circ}$ ano, com uma carga horária de duas horas semanais. A cadeira de História e Filosofia da Ciência foi programada para o quarto ano das licenciaturas em Física e em Química; e para $05^{\circ}$ ano das licenciaturas em Biologia e em Geologia, sempre com uma carga horária de duas horas semanais ao longo de todo 0 ano. Visto serem disciplinas do $4 .{ }^{\circ}$ e do $5 .{ }^{\circ}$ ano, só começariam a ser leccionadas a partir dos anos lectivos de 1967-1968 e 1968-1969 respectivamente, o que dava algum tempo para a Faculdade escolher e preparar os seus professores.

Em 1971 foi publicada uma nova alteração aos planos curriculares e à orgânica dos bacharelatos e licenciaturas (decreto n. ${ }^{\circ}$ 443/71), por José Veiga Simão, professor de Física da Universidade de Coimbra e então Ministro da Educação Nacional. Para a licenciatura em Matemática surgiu a disciplina História do Pensamento Científico ou História do Pensamento Matemático ( $3 .^{\circ}$ ano, $1 .^{\circ}$ semestre, três horas semanais), mas para as restantes licenciaturas de Física, Química, Biologia e Geologia desaparece a disciplina de História da Ciência.

O Anuário da Universidade de Coimbra, publicação sobre a vida académica desta instituição (publicado desde 1866 e contendo abundantes informações sobre professores, alunos, disciplinas, etc.), não foi editado entre os anos de 1966 e 1972, pelo que não conseguimos saber se as disciplinas projectadas no decreto n. ${ }^{\circ} 45840$ foram efectivamente leccionadas e por quem. No Arquivo da Universidade de Coimbra também não conseguimos encontrar fontes que clarificassem estas questões. Todavia, através do Anuário para o ano lectivo de 1972-197352, verificamos que o professor da disciplina de História do Pensamento Científico ou História do Pensamento Matemático foi Luís de Albuquerque, que entretanto tinha regressado de África. Curiosamente encontramos aqui a disciplina de História do Pensamento Científico, como opção no $3 .^{\circ}$ ano da licenciatura em Geologia, que foi ministrada pelo mesmo professor 53 .

\section{CONSIDERAÇÕES FINAIS}

52 Anuário da Universidade de Coimbra: 1972-1973 (1975), 271.

53 Ibid., 283. 
As lições livres de Armando Cortesão e de Reyer Hooykaas introduziram na Faculdade de Ciências da UC um pensamento estruturado, crítico e epistemológico sobre a História da Ciência. Contribuíram para a política educativa nacional de forma a incluir estudos sobre a História da Ciência, no programa obrigatório dos alunos das áreas científicas (com excepção das engenharias, para as quais a História da Ciência nunca foi uma prioridade).

No entanto, este avanço educacional não vingou e a remoção, em 1971, de uma disciplina com conteúdos em História da Ciência na maior parte das licenciaturas, representou um retrocesso nas intenções defendidas por Hooykaas, para quem (segundo as palavras de Albuquerque):

All the progress achieved starts from the lower steps which man has climbed throughout the centuries and finally they will prove to him that in order to obtain a better result of his effort as a scientist it will be convenient for him to know, as least in general way, the history of his own science with its hopes, conquests and recoils. ${ }^{54}$

Não sabemos as razões pelas quais esta disciplina foi retirada dos programas curriculares dos cursos de Ciências. Talvez a falta de professores vocacionados, ou uma carga horária excessiva, provocada pela introdução de disciplinas mais práticas e menos generalistas, tenham sido decisivas para a remoção da disciplina de História da Ciência do ensino universitário. Mas vale a pena ainda hoje ler as palavras de Luís de Albuquerque:

History of Science is built upon the facts and documents; it should not increase the value or decrease the importance of the individual scholar; it imposes on its cultivator the duty to plunge into the past, forgetting for the moment what has been discovered subsequently; and finally to give up the prejudice of classifying as absurd certain ideas that time destroyed but that were perfectly plausible at the time when the scientist built their theories upon them. .5

Agradecimentos: Os autores agradecem a Carlos Tenreiro, professor de Matemática da UC, as valiosas informações prestadas.

\footnotetext{
54 Luís de Albuquerque, introdução para Reyer Hooykaas - Select Studies in History of Science (Coimbra: Universidade de Coimbra, 1983).

${ }^{55}$ Ibid., X.
} 


\section{Sobre os autores:}

Gilberto Pereira

Museu da Ciência da UC / Centro de Física da Universidade de Coimbra

ggpereira@ci.uc.pt

Décio Martins

Centro de Física da Universidade de Coimbra / Departamento de Física da UC decio@uc.pt

Carlos Fiolhais

Museu da Ciência da Universidade de Coimbra

Centro de Física da Universidade de Coimbra / Departamento de Física da UC

tcarlos@uc.pt 